\title{
A mix of community-based conservation and protected forests is needed for the survival of the Endangered pygmy hippopotamus Choeropsis liberiensis
}

\author{
Annika Hillers, Graeme M. Buchanan, Jerry C. Garteh, Solomon M. Tommy \\ Mohamed L. Fofana and Jeremy A. Lindsell
}

\begin{abstract}
The contribution of protected areas to biodiversity conservation is well attested but many taxa in many regions remain dependent on the unprotected wider landscape. To develop conservation plans for large mammals such as the Endangered pygmy hippopotamus Choeropsis liberiensis of West Africa's Upper Guinea Forests it is critical to understand the importance of unprotected land. Despite being a conservation priority, little is known about the habitat associations of this species, or its distribution across its range. Through a combination of field surveys, species distribution models and community questionnaires we investigated the use of unprotected areas by the pygmy hippopotamus in the Sierra Leone-Liberia border region. We found signs of the species in 128 of $5251-\mathrm{km}^{2}$ cells surveyed. Our analysis suggested that the species is reasonably widespread in this region and is associated with major rivers. It occurred close to, but rarely within, large areas of intact forest, and $80.4 \%$ of pygmy hippopotamus signs were recorded outside protected areas. The expansion of the protected area network in this area is unrealistic in Sierra Leone and to some extent in Liberia, mainly because of anthropogenic pressure and the overlap of proposed protected areas with mining and logging concessions. Thus pygmy hippopotamus conservation activities in the region need to include programmes on community lands while maintaining a robust network of protected forests. Community-based conservation of the pygmy hippopotamus may prove valuable for other threatened and endemic species that are not confined to protected areas in this region.
\end{abstract}

Annika Hillers* (Corresponding author) and Graeme M. Buchanan RSPB Centre for Conservation Science, The Royal Society for the Protection of Birds, The Lodge, Sandy, Bedfordshire, SG19 2DL, UK

E-mail annika.hillers@rspb.org.uk

JERRY C. GARTEH Society for the Conservation of Nature of Liberia, Congotown, Monrovia, Liberia

Solomon M. Tommy and Mohamed L. Fofana, Gola Rainforest National Park, Kenema, Sierra Leone

Jeremy A. Lindsell A Rocha International, London, UK

*Also at: Gola Rainforest National Park, Kenema, Sierra Leone

Received 20 July 2015. Revision requested 28 September 2015.

Accepted 15 February 2016. First published online 7 June 2016.
Keywords Agricultural expansion, community-based conservation, community forests, large mammals, protected area, pygmy hippopotamus, species distribution model, Upper Guinea Forest ecosystem

To view supplementary material for this article, please visit http://dx.doi.org/10.1017/So03060531600020X

\section{Introduction}

D rotected areas are the foundation for global efforts to 1 conserve biodiversity and natural ecosystem processes (Rodrigues et al., 2004; Laurance et al., 2014). However, analysis of threatened birds, mammals, amphibians and reptiles at both continental and global scales suggests that protected areas offer inadequate coverage of the ranges of these groups (De Klerk et al., 2004; Rodrigues et al., 2004; Beresford et al., 2011a,b; Butchart et al., 2015). Multiple-use landscapes and unprotected areas are important for species survival (Gardner et al., 2007; Perfecto \& Vandermeer, 2010), especially where the existing network of protected areas does not entirely cover species' ranges and suitable habitats; e.g. for some large mammalian carnivores (Forrest et al., 2011; Swanepoel et al., 2013) and migratory herbivores (Western et al., 2009). In some cases the expansion of the protected area network is recommended for more effective protection (Forrest et al., 2011; Tweh et al., 2015) but this may not always be feasible (Butchart et al., 2015), especially in regions where conservation efforts compete with other land uses, such as logging, mineral extraction and agriculture. In many tropical regions, such land use conflicts represent a threat not only to remaining natural habitats outside protected areas but even to the protected areas themselves (Forrest et al., 2011; Laurance et al., 2012; Tweh et al., 2015). A rapidly increasing human population is predicted to result in a further major expansion of tropical agriculture and associated encroachment of protected areas, particularly in Sub-Saharan Africa and South America (Laurance et al., 2014). The persistence of large mammals in such regions will therefore depend to a great extent on their ability to survive in such mixed landscapes.

Within the forest zone of West Africa, protected areas cover c. $15 \%$ of the remaining Upper Guinean Forest 
ecosystem (CEPF, 2000). In Liberia and Sierra Leone only 2 and $5 \%$ of the total land area, respectively, is officially protected (Junker et al., 2015; UNEP, 2015). These figures suggest that the protected area coverage in the region is inadequate, and falls below the Convention on Biological Diversity Aichi Target of at least $17 \%$ (CBD, 2010). Meanwhile, forests in this region have been severely depleted and fragmented in recent decades (Mittermeier et al., 2004). Where forests are cleared they are replaced with low-intensity rotational agriculture.

The remaining forests harbour a number of threatened large mammals, some of which are known to range beyond the bounds of protected areas (Merz, 1986; Junker et al., 2012, 2015). Of these, the pygmy hippopotamus Choeropsis liberiensis, categorized as Endangered on the IUCN Red List (Ransom et al., 2015), is the largest species that is entirely endemic to the Upper Guinean Forest and is therefore amongst the most vulnerable to habitat loss and fragmentation in the region. The pygmy hippopotamus is restricted to four countries (Sierra Leone, Liberia, Guinea and Côte d'Ivoire; Lewison \& Oliver, 2008), all of which are among the least developed countries in the world (UNDP, 2014). In recent decades, forest loss and fragmentation have contributed to a reduction in the occupied range of the species (Lewison \& Oliver, 2008; Mallon et al., 2011; Hodgkinson et al., 2013). The pygmy hippopotamus is also threatened by poaching and human-wildlife conflicts (e.g. Greengrass, 2011; Hillers \& Muana, 2011; Koroma, 2012; Conway, 2013; Conway et al., 2015), although there are no detailed data concerning the extent of these threats. Little is known about the ecology and behaviour of the pygmy hippopotamus, and there are no reliable population estimates. The most recent estimate is $2,000-3,000$ individuals (Mallon et al., 2011). The prevailing view is that protected areas harbour the majority of the population (Mallon et al., 2011; IUCN, 2014) but the importance of habitats outside protected areas remains unclear. Although most recent records have come from within protected areas (Collen et al., 2011; Mallon et al., 2011) this may represent sampling bias, as such sites are often targeted for biodiversity surveys. Furthermore, riverine habitats can be poorly represented in protected areas (Nel et al., 2007) but are presumably critical for the pygmy hippopotamus, and in fact protected area status can mean little in a region where many are poorly funded and ineffective (Brugière, 2012; Henschel et al., 2014).

We undertook surveys for the pygmy hippopotamus both within and outside protected areas to clarify the importance of unprotected areas for this species. We conducted this work in the western part of the species' range within Sierra Leone and western Liberia (Lewison, 2011). Distribution information from this area is patchy and outdated (e.g. Grubb et al., 1998) but evidence has emerged that besides a well-known site at Tiwai Island (Conway et al., 2015) the area around the Gola Rainforest National Park in south-eastern Sierra Leone, and presumably also the Gola National Forest in western Liberia, may constitute an important core area for the species (Hillers, 2013). The discovery of what could be a substantial population highlights how poorly known the species' distribution is.

We used records of pygmy hippopotamus occurrence collected during field surveys and using community questionnaires to assess the species' distribution in the Gola region. We used field data to develop species distribution models that predicted the potential distribution of the pygmy hippopotamus, and described the species' basic habitat associations. We were thus able to identify the extent to which the pygmy hippopotamus might occur in protected and unprotected areas, and where suitable habitat was located both inside and outside the protected area network. Besides advancing our understanding of the role of unprotected areas in general biodiversity conservation in this region, these data are critical if targeted and effective conservation interventions are to be implemented for this species in particular.

\section{Study area}

We conducted field work in the Gola Rainforest National Park and its surroundings (c. 1,210,00o ha) in south-eastern Sierra Leone and in the Gola National Forest (initially c. 980,000 ha) in western Liberia, the whole area hereafter referred to as Gola (Fig. 1). After the completion of field work, the area of the Gola National Forest was reduced by 100,000 ha and part of our survey sites that were initially inside the protected area now fall within community land. Natural vegetation in Gola is lowland moist evergreen forest, and annual rainfall is c. $3,000 \mathrm{~mm}$, falling in one season. Dominating families of the woody vegetation are Leguminosae-Caesalpinoideae, Euphorbiaceae, LeguminosaeMimosoideae and Sterculiaceae (Klop et al., 2008). The study area is drained by three major rivers: the Moa River to the west; the Moro River, marking the boundary between Sierra Leone and Liberia in the eastern part of Gola; and the Mano River, flowing through the Liberian Gola National Forest and along the international border in the western part of Gola.

\section{Methods}

Data on the distribution of the pygmy hippopotamus were collected by field surveys during 2010-2014 and community questionnaires administered in 2010.

\section{Field surveys}

Distribution data were collected by walking along streams and riversides within and around the Gola Rainforest National Park during July 2010-June 2011 and May 2013-April 2014, 


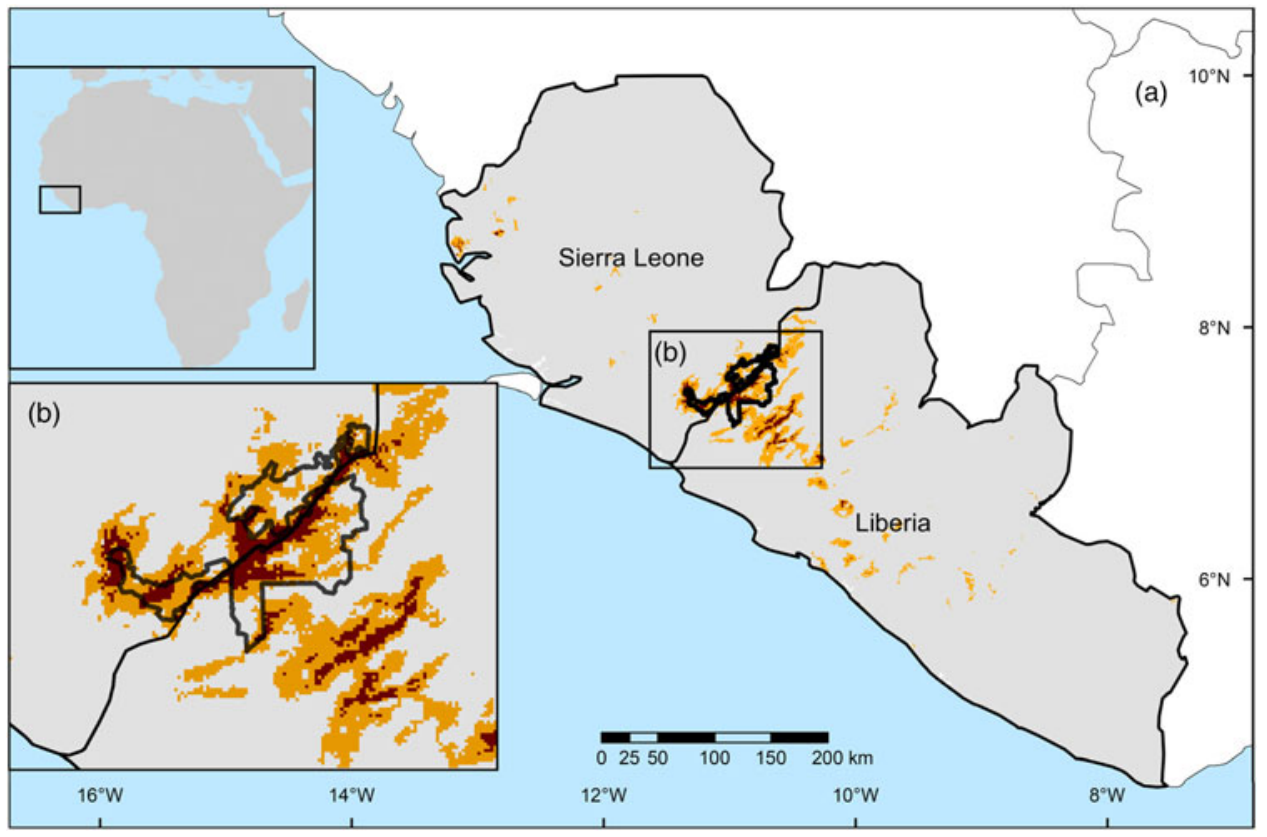

FIG. 1 (a) Location of the Gola Forests in Sierra Leone and Liberia in West Africa, and the predicted distribution of the pygmy hippopotamus Choeropsis liberiensis in both countries. (b) The study area around the Gola Rainforest National Park and the Gola National Forest. Areas predicted by the model at the 0.2 threshold and above the 0.57 threshold are indicated by light and dark shading, respectively. searching carefully for signs of the species (footprints, trails, dung, feeding sites, wallows, direct sightings), especially where the substrate might preserve footprints or conditions were suitable for a wallow or foraging. We searched sites along the length of the Moro and Mano rivers, tributaries draining the National Park both within and outside the protected area, and parts of the Moa River. These surveys complemented work conducted on and around Tiwai Island (Conway, 2013; Conway et al., 2015).

In 2010 and 2011 field surveys were partly informed by community questionnaires (below) as the field teams also conducted surveys to confirm the presence of pygmy hippopotamus at places where respondents had stated they had recently seen the species.

Where pygmy hippopotamus signs were found the predominant habitat type was recorded as (1) forest (healthy primary or secondary forest after selective logging), (2) farm bush (regrown vegetation after agricultural rotational activities), (3) plantations of non-natural vegetation, such as oil palm and cocoa, or (4) rivers, streams and swamps, without clear definition of the surrounding habitat type (Hillers \& Muana, 2011; Hillers, 2013).

Focal survey data were supplemented with ad hoc observations from general biodiversity survey data (Fig. 2) from 2010-2014. A terrestrial mammal survey using camera traps covered $272 \mathrm{~km}^{2}$ of Gola Rainforest National Park, Gola National Forest and the intervening community lands during 2011-2013 (Hillers, 2013). Camera traps (PC8oo Hyperfire, Reconyx Inc., Holmen, USA) were placed for c. 35 days each at the centre of $1 \times 1 \mathrm{~km}$ grid cells (located using a global positioning system), using camera positions unbiased by animal signs (Wearn et al., 2013).
We recorded direct observations (sightings and auditory) and signs (dung, prints, trails, wallows, nests, feeding sites) of all larger mammals ( $>$ c. $5 \mathrm{~kg}$ ) along 11 straight transects in Gola Rainforest National Park, seven transects in community areas (of which five were initially inside the protected Gola National Forest before the protected area was reduced) and 6o transects in Gola National Forest during April 2011-July 2012. Transects were usually $2 \mathrm{~km}$ long (13 transects were shorter, 485-1,960 $\mathrm{m}$, because of their location along rivers or borders of the National Park) and 2.5 $\mathrm{km}$ apart, arranged on a systematic grid (Hillers, 2013).

Opportunistic observations were recorded throughout the study area (Fig. 3) when signs of pygmy hippopotamus were observed outside the sampling framework of particular surveys (Hillers, 2013).

\section{Modelling the potential distribution of the pygmy hippopotamus using field survey data}

All of the presence data recorded during the field surveys were used to train maximum entropy models in Maxent 3.3.2 (Phillips et al., 2006; Phillips \& Dudik, 2008). Community questionnaire data were not used in the modelling. Environmental conditions (Table 1 ) in occupied $1-\mathrm{km}^{2}$ cells (the resolution of the analysis) were compared to those at 10,000 randomly generated pseudo absence points within the model building area (Supplementary Fig. S1), before extrapolation to the whole of Sierra Leone and Liberia. The method of data collection may have introduced some biases into the data (e.g. footprints more likely to be detected in soft substrates) but Maxent appears to be robust to data collected in such an ad hoc way (Franklin, 2009). 


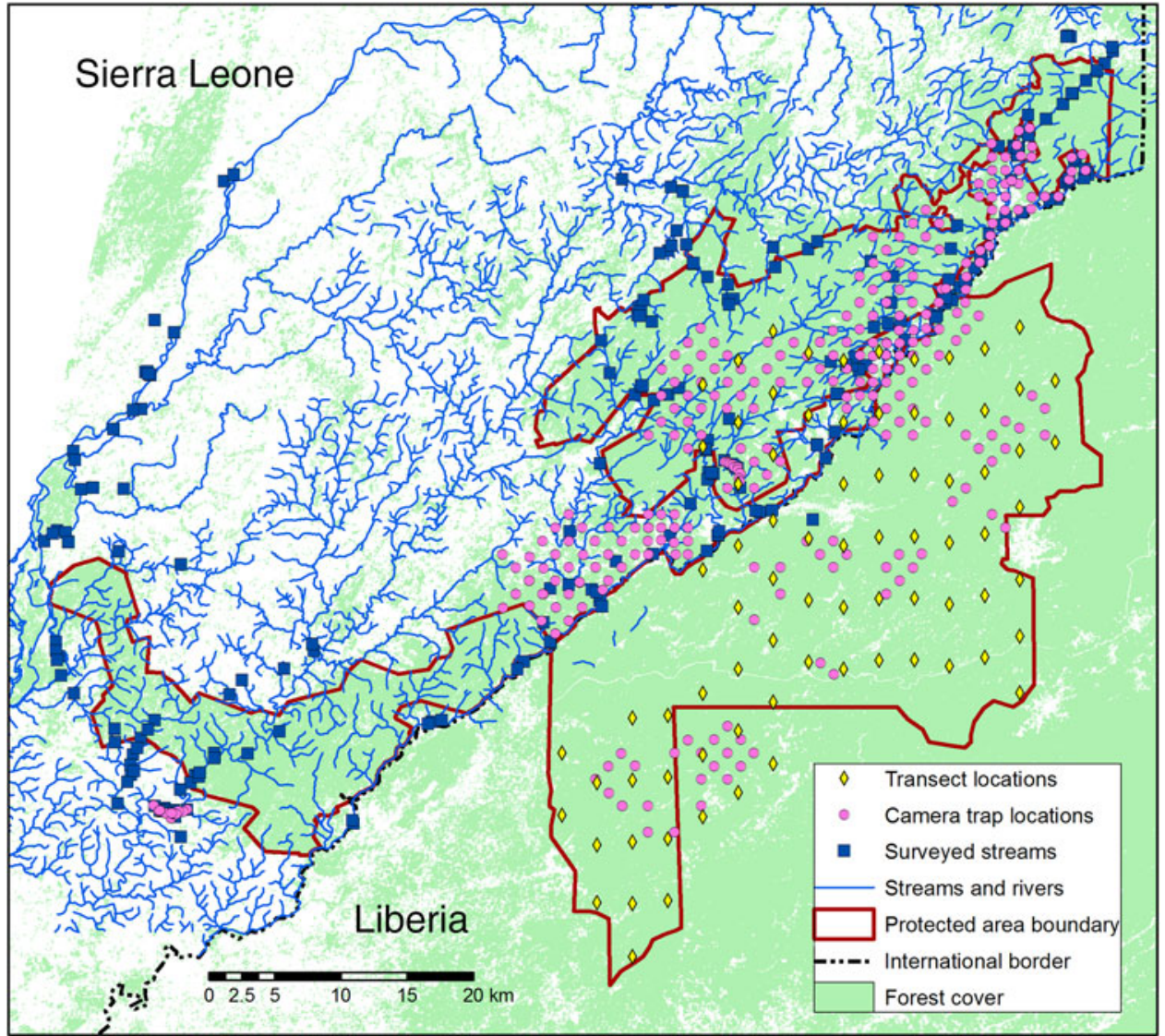

FIG. 2 Locations of transects, camera traps, and streams surveyed for the pygmy hippopotamus in and around the Gola Rainforest National Park in Sierra Leone and the Gola National Forest in Liberia.
Only variables that explained at least $1 \%$ of the model gain were retained in the final model using backwards deletion (Table 2). The potential of model overfitting was reduced by altering the beta multiplier. A value of 5 produced smooth response curves. The final model was run with 10 cross validations (i.e. the model was re-run 10 times with a different $10 \%$ of records removed each time). The mean logistic output from all 10 models was used to produce a binary map of potential distribution, based on the mean training data equal sensitivity and specificity threshold. The number of pygmy hippopotamus in the Gola region was estimated by extrapolation of the extent of potentially suitable habitat and estimates of home range size (Roth et al., 2004): females 40-60 ha (midpoint 50 ha used), males $>150$ ha, although home ranges of individuals can overlap.

\section{Community questionnaires}

Semi-structured questionnaires were administered in 103 communities around Gola Rainforest National Park during July-November 2010. Communities within $4 \mathrm{~km}$ of the National Park boundary and/or $2 \mathrm{~km}$ of major streams were selected, to increase the probability of encountering people with knowledge of the pygmy hippopotamus.

Only respondents who could identify a pygmy hippopotamus from a set of pictures of large mammals were questioned. They were asked to answer the questions only in relation to the community where the questionnaire was being administered. Interviews were conducted in the local language by National Park staff members. It was stated clearly that the purpose of the questionnaires was not prosecution or punishment and that no personal details of respondents were recorded. Questionnaires were designed and administered following the guidelines of the Association of Social Anthropologists of the UK \& Commonwealth (1999).

Respondents were asked about encounters with pygmy hippopotamus (recent and historical) in their locality, behaviour, activity patterns, habitat preferences, diet, and changes in the abundance of pygmy hippopotamus. They were also asked about human-wildlife conflicts, hunting of pygmy hippopotamus, their general attitude towards pygmy hippopotamus, and any traditional uses and beliefs pertaining to the species. Initial questions about each of these subjects could be answered either yes or no, with yes responses leading to additional questions. Answers regarding traditional uses and beliefs, general attitudes towards the pygmy hippopotamus, and the species' diet are not reported here.

Responses about encounters with the pygmy hippopotamus were mapped and reports of the species' presence were investigated by field visits. Community localities were categorized as those where the pygmy hippopotamus 


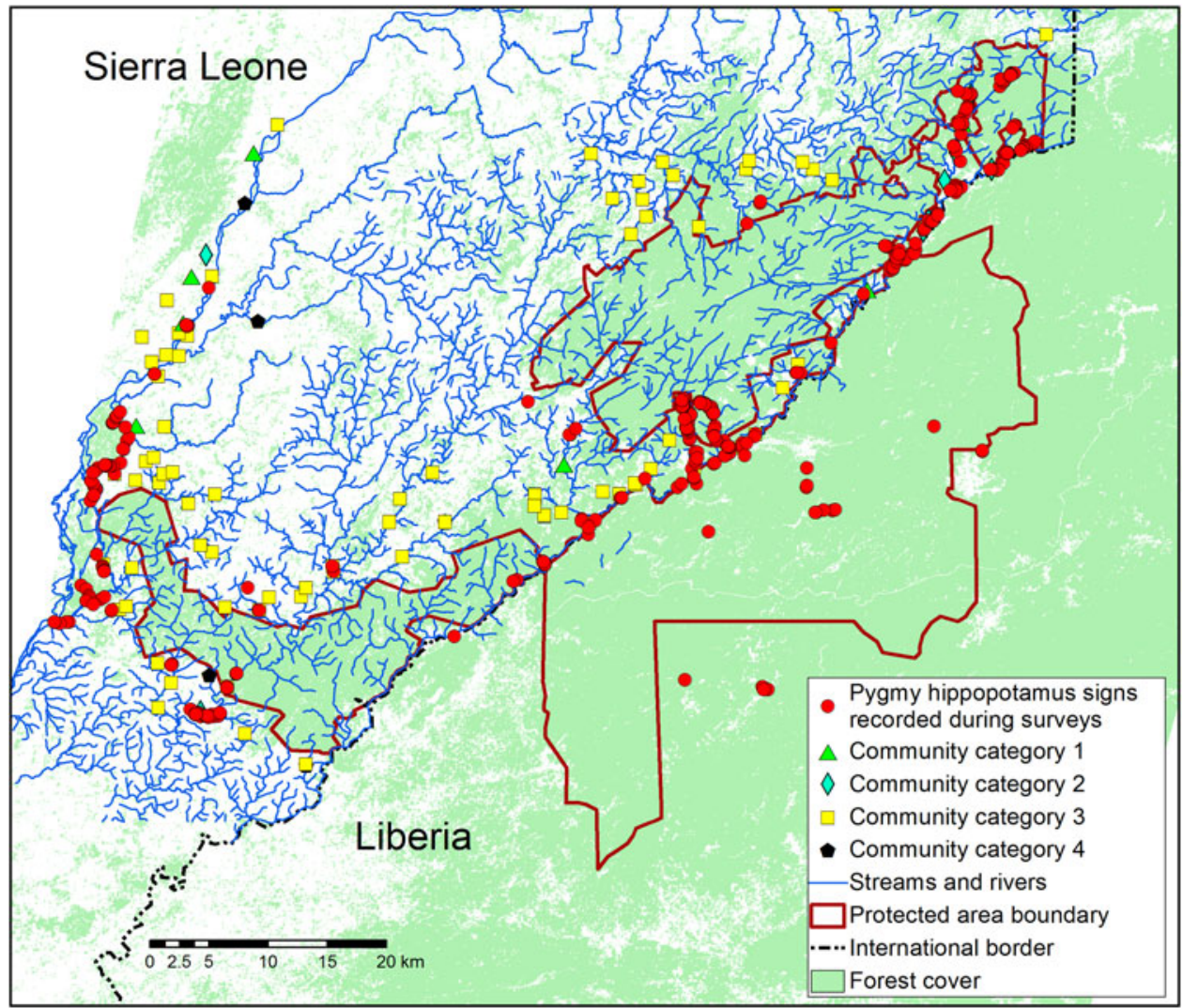

FIG. 3 Distribution of communities in the Gola region (Fig. 1) where questionnaires about the pygmy hippopotamus were administered, and locations where signs of pygmy hippopotamus were recorded during field surveys. Communities are categorized as (1) those where the pygmy hippopotamus was observed both in the past and at present and fresh signs were recorded, (2) those where the pygmy hippopotamus was observed both in the past and at present but no fresh signs were recorded, (3) those where the pygmy hippopotamus was observed in the past but is no longer present, or (4) those where the pygmy hippopotamus was not observed either in the past or at present. Drainage is shown for a portion of the region for which data were available.

TABLE 1 Explanatory variables used for entropy models.

\begin{tabular}{lllll}
\hline Class & Variable & Product & Source & Date acquired \\
\hline Land cover & Maximum monthly Normalized Difference & SPOT (2010) & VITO Earth Observation (2010) & 13 Sep. 2013 \\
& $\begin{array}{l}\text { Vegetation Index } \\
\text { Euclidean distance to forest }\end{array}$ & GLC2000 & Mayaux et al. (2004) & DiVA-GIS (2013) \\
Euclidean distance to water & DIVA & DIV. 2013 \\
Topography & Slope, elevation & HYDRO1 K & USGS (2013) & 17 Sep. 2013 \\
Climate & $\begin{array}{l}\text { Mean annual + monthly variation in } \\
\text { temperature \& precipitation }\end{array}$ & Bioclim & Hijmans et al. (2005) & 13 Sep. 2013 \\
& & & & \\
\hline
\end{tabular}

(1) had never been reported, (2) was reported in the past, (3) was reported to be present but was not verified during field surveys, or (4) was reported and verified as present.

\section{Results}

Observed and modelled distribution of the pygmy hippopotamus

Field surveys, including camera trapping, covered $5251-\mathrm{km}^{2}$ grid cells. Pygmy hippopotamus and their signs were recorded at 509 locations in 128 of these cells (Fig. 3). Eight of these locations were verified following information received through the community questionnaires. At the 509 locations,
$69.9 \%$ of signs were footprints or trails, $8.6 \%$ were dung, $7.6 \%$ were feeding sites, $1.7 \%$ were direct sightings or camera-trap photographs, and $0.4 \%$ were wallows. The remaining signs $(11.8 \%)$ were not specified. In some cases multiple signs were recorded at the same location $(28.7 \%)$.

Habitat descriptions were available for 409 record locations, with the majority of records found in farm bush areas $(243 ; 54.41 \%)$, followed by forest ( $99 ; 24.21 \%)$, and rivers, streams and swamps $(66 ; 16.14 \%)$. Only one record of pygmy hippopotamus presence was from a plantation (cocoa).

Footprints (45.8\%), feeding sites $(51.6 \%)$ and dung (54.2\%) were mainly recorded in farm bush areas (Fig. 4), whereas direct sightings and camera-trap photographs were mainly recorded in the forest (78.6\%). Pygmy hippopotamus trails were mostly recorded in farm bush areas 
TABLE 2 Variables included in the model of pygmy hippopotamus Choeropsis liberiensis distribution, with percentage contribution and permutation importance.

\begin{tabular}{llc}
\hline Variable & \% contribution & $\begin{array}{c}\text { Permutation } \\
\text { importance }^{2}\end{array}$ \\
\hline Temperature variation & 23.2 & 15.3 \\
Annual rainfall & 20.9 & 6.6 \\
Distance to forest & 15.6 & 29.9 \\
Distance to river & 12 & 8.3 \\
Mean temperature & 11 & 10.1 \\
Feb. normalized difference & 7.7 & 2.7 \\
vegetation index (NDVI) & & \\
Altitude & 4.6 & 5.3 \\
Rain variation & 2.2 & 21.5 \\
Apr. NDVI & 1.7 & 0.2 \\
Dec. NDVI & 1.1 & 0.2 \\
\hline
\end{tabular}

${ }^{1}$ In each iteration of the training algorithm the increase in regularized gain was added to the contribution of the corresponding variable, or subtracted from it if the change to the absolute value of lambda was negative.

${ }^{2}$ For each variable in turn, the values of that variable on training presence and background data were randomly permuted. The model was reevaluated on the permuted data, and the resulting drop in training AUC is shown, normalized to percentages.

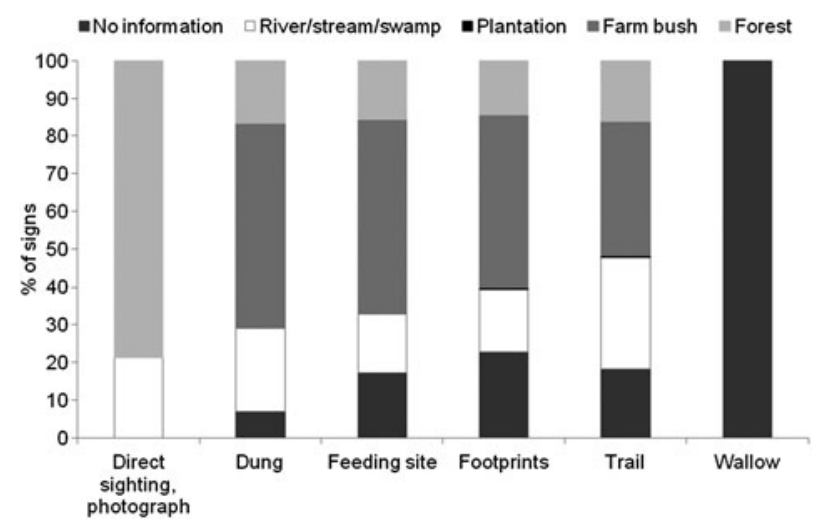

FIG. 4 Percentage of various types of pygmy hippopotamus signs recorded in various habitat types.

(35.7\%) and along rivers, streams and swamps (29.3\%). However, the habitats surrounding rivers, streams and swamps were not specified and could be either forest or farm bush areas.

The majority of record locations $(412 ; 80.4 \%)$ were outside the boundary of the protected areas. The locations were clustered along the larger streams and rivers, such as the Mano and Moro Rivers bordering Sierra Leone and Liberia, and the Moa River.

Modelled pygmy hippopotamus distribution, based on the 128 occupied $1-\mathrm{km}^{2}$ cells, was most strongly associated with climatic variables and distance to rivers and closed forest, with response curves indicating that areas closer to rivers and forest were more likely to be occupied (Fig. 2). Distance to rivers and to closed forests made a similar percentage contribution to the model (Table 2), perhaps indicating that both variables were of similar importance in determining the distribution (although distance to forest might have been marginally more important given that it makes a larger contribution under permutation testing).

The species distribution model across the 10 crossvalidation runs had a mean AUC (area under the curve) of $0.985 \pm \mathrm{SD} 0.006$, indicating the model was a reasonable fit to the data. At the equal sensitivity and specificity threshold (0.206) there was $6,453 \mathrm{~km}^{2}$ of potentially occupied habitat across Sierra Leone and Liberia. The model correctly identified 121 of the 128 locations with sightings but it incorrectly predicted 302 of the 397 apparently unoccupied squares (locations surveyed but at which no signs of pygmy hippopotamus were recorded) to be occupied. This can arise where suitable habitat is unoccupied or where pygmy hippopotamus were undetected in occupied sites, or it may indicate that the model had high sensitivity but low specificity (i.e. it overpredicted potential distribution). A comparison of likelihood of occupancy at these apparent absences with the values at confirmed presences (rather than pseudo absences from the model building process) produced an ROC (receiver operating characteristic) to 0.71 , with a revised equal sensitivity and specificity threshold of 0.57 . At this threshold $66 \%$ of both presences and absences were correctly predicted, and $1,097 \mathrm{~km}^{2}$ across Sierra Leone and Liberia were identified as potentially occupied by the pygmy hippopotamus. This indicates there may be habitat for c. 2,000 female and fewer than c. 600 male pygmy hippopotamus across the two countries. Many of these patches are small and isolated (Fig. 1), perhaps rendering them unsuitable. By far the largest area of potentially suitable habitat is around the Gola region (Fig. 1), where much of the suitable habitat falls outside Gola Rainforest National Park and Gola National Forest (Fig. 1b).

\section{Community perceptions of pygmy hippopotamus distribution}

In the majority of communities (78) 2-10 respondents were interviewed. In the remaining 25 communities only one respondent was interviewed, based on the ability to identify a pygmy hippopotamus. Of 271 respondents in 103 communities only five communities reported that pygmy hippopotamus were not currently present or had never been present. Eighty-one communities reported that pygmy hippopotamus were present in the past but were no longer present, and 17 reported that pygmy hippopotamus were present at the time of the study but signs of presence were found in only eight of these locations during follow-up surveys (Fig. 2). Communities where the pygmy hippopotamus was considered (or proven) to be extant were mainly located along the Mano, Moro and Moa Rivers and nearer to the 
border with Liberia (Fig. 2). The majority of the reported extinctions were along the more heavily settled northern boundary of Gola Rainforest National Park. However, field surveys indicated that the species persists in part of this area (Fig. 2). Over $50 \%$ of respondents $(148 ; 54.61 \%)$ believed that pygmy hippopotamus were less common than in the past. Respondents attributed the decline to logging (especially the noise of power saw operation; 72 respondents), farming (65), hunting (40), expansion and creation of settlements (11), general habitat destruction and deforestation (5), the sound of guns and shooting during the war (4), mining (3), as well as natural deaths (1) and dry streams (1).

\section{Discussion}

Field surveys, species distribution models, and community questionnaires all indicate that in the Gola region the pygmy hippopotamus is generally found in association with streams or swampy areas, mostly outside protected areas, and in close proximity to forests (including protected forests). Closed forest, although of equal or perhaps greater importance than proximity to streams and rivers according to the models, was not the most frequented habitat according to field surveys. However, with the modelling approach used we were unable to definitively identify which was more important. The outputs of the distribution model are supported by the field observations and suggest that the most suitable habitat is in the unprotected, community-owned landscape. In particular, the area along the Moro and Mano Rivers between Sierra Leone and Liberia was predicted to contain extensive habitat suitable for the pygmy hippopotamus. Some of the apparent selection for streams and swampy areas, especially in the analysis of field surveys, might have been because of the targeting of these areas for surveys. These biases might have continued to have an influence on the species distribution models but comparison of occupied areas with such a large number of pseudo absences should reduce the impact of this potential bias. Larger streams and lowland areas are more prevalent in Gola National Forest than Gola Rainforest National Park, which may explain the greater number of detections in the former, despite the higher hunting pressure there (Hillers, 2013; Lahai, 2013). Elsewhere in its range the pygmy hippopotamus is reported to use even small streams under forest cover (Roth et al., 2004).

The pygmy hippopotamus' preference for mainly unprotected farm bush areas may also be linked to the presence of the herbaceaous plant Triumfetta cordifolia (family Tiliaceae; kPuhun in the local language; Hillers \& Muana, 2011). Local people identified this plant as an important food plant for the pygmy hippopotamus.

Our species distribution model is based on data from a small area, and therefore caution should be applied in extrapolating the results to the rest of the pygmy hippopotamus' range. Areas mapped as potentially suitable (such as around the coast of Sierra Leone) may be covered by habitat that is broadly suitable for the species, yet it may be absent for reasons such as hunting pressure or fragmentation. Of perhaps greater concern is the failure of the model to identify areas in eastern Liberia (e.g. Sapo National Park, Grebo National Forest) where the pygmy hippopotamus is known to occur. The reasons for this are worth investigating but may be linked to differences in land cover (e.g. larger connected forest areas in eastern Liberia).

Our population estimate for the pygmy hippopotamus in Sierra Leone and Liberia alone was close to the estimated global population, which includes populations in Guinea and Côte d'Ivoire. There are a number of possible explanations for this apparent discrepancy between local and global population estimates. Firstly, our model may have overestimated the potential extent of suitable habitat, even after assessing the model based on known absences. Secondly, our model only examined habitat and did not include data on potential exploitation, such as hunting for bushmeat. Thus, although there might be suitable habitat to support a high number of individuals, the actual numbers may be lower as a result of hunting. Under these circumstances, control of hunting could result in an increase in the population. Finally, it is possible that the models were adequate but that the density estimates from previous studies (Roth et al., 2004) were unrealistically high and that the previous population estimate is incorrect. With one exception the home range estimations of Roth et al. (2004) were based on translocated individuals. It may be possible that in its natural habitat the pygmy hippopotamus has larger home ranges, which would affect our model and lead to lower estimates of population sizes. Field surveys are needed in areas predicted to be occupied as well as those predicted to be unoccupied, to test the model thoroughly, and improved density estimates in various habitat types are needed. Future field surveys should be structured, using standardized methods. The data used in this analysis were collected by multiple methods, in different years and by multiple observers. Consequently there may be unquantified errors and biases in our data. However, we modelled the data using an approach that has been shown to work well with ad hoc survey data (Franklin, 2009), and at a broad spatial resolution (1 km cells).

The Conservation Strategy for the Pygmy Hippopotamus (Mallon et al., 2011) indicates that most recent records of the species are from protected forest areas, and puts considerable emphasis on the importance of protected areas in managing this species. Expansion of the protected area network to cover a greater area of forest should be encouraged, especially in light of the reported low coverage of Sierra Leone and Liberia by protected areas (Junker et al., 2015; UNEP, 2015). Whereas forests in Sierra Leone, Guinea and Côte d'Ivoire are highly fragmented and under significant 
anthropogenic pressure (Mallon et al., 2011), Liberia still has large blocks of forest in the north-west and south-east (Christie et al., 2007). The Liberian government committed to the protection of $30 \%$ of remaining forests in 2003 and again in 2014 (Junker et al., 2015). However, proposed protected areas largely overlap with logging and mining concessions, which jeopardizes further declarations of protected areas.

It may be unfeasible to expand the global protected area network to cover all sites of importance and capture species' ranges adequately (Butchart et al., 2015). However, our analysis showed that although the pygmy hippopotamus may rely on forest to some unknown extent, protecting forests alone will not protect all of the pygmy hippopotamus' habitats. Thus, in addition to maintaining a robust network of protected forests, conservationists should also consider community land close to protected areas, especially wet areas along rivers. The complementary conservation value of unprotected areas has previously been shown in various locations and for various species (e.g. Gardner et al., 2007; Perfecto \& Vandermeer, 2010; Forrest et al., 2011), and this and other recent surveys have indicated the importance of habitats outside protected areas for threatened species in Sierra Leone and Liberia. More than half of the 70 known breeding colonies of the Vulnerable white-necked picathartes Picathartes gymnocephalus in the Gola region are located on community land around Gola Rainforest National Park (Monticelli et al., 2012; Hillers, 2013), and in Liberia a nationwide survey of large mammals revealed that the majority (70\%) of western chimpanzees Pan troglodytes verus and some of the most species-diverse mammal communities occur outside protected areas (Tweh et al., 2015).

There are successful examples of community conservation initiatives that have been applied in various forms and could also work in Sierra Leone and Liberia, including community sensitization and outreach programmes (Trewhella et al., 2005, Steinmetz et al., 2014), communitybased wildlife monitoring (Danielsen et al., 2014) and community-based natural resource management (e.g. through community conservancies and wildlife sanctuaries; Brown \& Bird, 2011; Garnier et al., 2012). In Ghana, at the eastern edge of the Upper Guinea Forest ecosystem, the establishment of a Community Resource Management Area process has proven to be a successful and promising tool for managing forest resources (Asare et al., 2013).

Such community-level approaches may also be more successful in addressing threats unrelated to habitat, such as hunting. Within the pygmy hippopotamus' range several environmental education and outreach programmes focusing on the species' conservation have been conducted (Steck, 2015). However, no follow-up research has investigated the impact and success of these programmes so far, and there is evidence that despite past and ongoing outreach programmes threatened species, including the pygmy hippopotamus, are still being hunted in the Gola region (Koroma, 2012; Hillers, 2013) and in other areas in Liberia (Greengrass, 2011).

Apart from some areas in north-western and southeastern Liberia, remaining forests in all pygmy hippopotamus range countries are highly fragmented (Mallon et al., 2011) and large-scale exploitation of timber and minerals, as well as the increasing need for agricultural land, are further threatening remaining natural habitats and their biodiversity (Laurance et al., 2014; Tweh et al., 2015). Therefore, it is likely that pressures on the pygmy hippopotamus will remain high. Consequently, in addition to the potential expansion of the protected area network in Liberia (Junker et al., 2015) community-based conservation activities and community management of unprotected sites, including effective land-use planning, are likely to become an important tool for conservation in West Africa. Approaches that empower communities as well as improving biodiversity should be encouraged, especially with a view to meeting the Sustainable Development Goals (UN, 2015).

\section{Acknowledgements}

This work was funded by Basel Zoo, Switzerland, and the European Union. We thank partners of the Gola Rainforest National Park and the project Across the River-A Transboundary Peace Park for Sierra Leone and Liberia: the Forestry Division of the Ministry of Agriculture, Forestry and Food Security, the Conservation Society of Sierra Leone, the Liberian Forestry Development Authority, the Society for the Conservation of Nature of Liberia, BirdLife International, Vogelbescherming Nederland and the Royal Society for the Protection of Birds. Andrew Muana, Sheku Massaquoi, Mohamed Kallon, Muana M. Konneh, Umaru Bockarie, Lahai Kanneh, Trokon S. Grimes, Alex T. Johnson, Mawehn B. Koenig, Aaron Dayeker, Daniel K. Harris, Mohamed Koroma, Mohamed F. Kallon and Prince Soriba helped with field data collection, with contributions from additional Gola Rainforest National Park research technicians, local guides, and Jessica Ganas. This paper is dedicated to our late colleagues Andrew Muana and Sheku Massaquoi.

\section{References}

Asare, R.A., Kyei, A. \& Mason, J.J. (2013) The community resource management area mechanism: a strategy to manage African forest resources for REDD+. Philosophical Transactions of the Royal Society B, 368, 20120311.

Association of Social Anthropologists of the UK \& Commonwealth (1999) Ethical Guidelines for Good Research Practice. Http://www.theasa.org/ethics/guidelines.shtml [accessed 21 March 2016].

Beresford, A.E., Buchanan, G.M., Donald, P.F., Butchart, S.H.M., Fishpool, L.D.C. \& Rondinini, C. (2011a) Poor overlap between the 
distribution of protected areas and globally threatened birds in Africa. Animal Conservation, 14, 99-107.

Beresford, A.E., Buchanan, G.M., Donald, P.F., Butchart, S.H.M., Fishpool, L.D.C. \& Rondinini, C. (2011b) Minding the protection gap: estimates of species' range sizes and holes in the protected area network. Animal Conservation, 14, 114-116.

Brown, J. \& Bird, N. (2011) Sustainable Natural Resource Management in Namibia: Successful Community-Based Wildlife Conservation. ODI Publications, London, UK.

Brugiére, D. (2012) Identifying priority areas for the conservation of antelopes in the Republic of Guinea, West Africa, using the complementarity approach. Oryx, 46, 253-259.

Butchart, S.H.M., Clarke, M., Smith, R.J., Sykes, R.E., Scharlemann, J.P.W., Harfoot, M. et al. (2015) Shortfalls and solutions for meeting national and global conservation area targets. Conservation Letters, 8, 329-337.

CBD (Convention on Biological Diversity) (2010) COP 10 Decision X/2. Strategic plan for biodiversity 2011-2020. Http://www. cbd.int/decision/cop/?id=12268 [accessed 1 October 2014].

CePf (Critical Ecosystem Partnership Fund) (200o) Upper Guinean Forest Ecosystem of Guinean Forests of West Africa Biodiversity Hotspot. CEPF, Washington, D.C., USA.

Christie, T., Steininger, M.K., Juhn, D. \& Peal, A. (2007) Fragmentation and clearance of Liberia's forests during 1986-200o. Oryx, 41, 539-543.

Collen, B., Howard, R., Konie, J., Daniel, O. \& Rist, J. (2011) Field surveys for the Endangered pygmy hippopotamus Choeropsis liberiensis in Sapo National Park, Liberia. Oryx, 45, 35-37.

Conway, A.L. (2013) Conservation of the pygmy hippopotamus (Choeropsis liberiensis) in Sierra Leone, West Africa. PhD thesis. University of Georgia, Athens, USA.

Conway, A.L., Hernandez, S.M., Carroll, G.P., Green, G.T. \& LARSON, L. (2015) Local awareness of and attitudes towards the pygmy hippopotamus Choeropsis liberiensis in the Moa River Island Complex, Sierra Leone. Oryx, 49, 550-558.

Danielsen, F., Jensen, P.M., Burgess, N.D., Altamarino, R., Alviola, P.A., Andrianandrasana, H. et al. (2014) A multicountry assessment of tropical resource monitoring by local communities. BioScience, 64, 236-251.

De Klerk, H.M., FJelds ̊, J., Blyth, S. \& Burgess, N.D. (2004) Gaps in the protected area network for threatened Afrotropical birds. Biological Conservation, 117, 529-537.

DIVA-GIS (2013) Http://www.diva-gis.org/gdata [accessed 18 September 2013].

Forrest, J.L., Bomhard, B., Budiman, A., Coad, L., Cox, N., Dinerstein, E. et al. (2011) Single-species conservation in a multiple-use landscape: current protection of the tiger range. Animal Conservation, 14, 283-294.

Franklin, J. (2009) Mapping Species Distributions. Cambridge University Press, Cambridge, UK.

Gardner, T.A., Caro, T., Fitzherbert, E.B., Banda, T. \& Lalbhai, P. (2007) Conservation value of multiple-use areas in East Africa. Conservation Biology, 21, 1516-1525.

Garnier, J., Hill, N., Guissamulo, A., Silva, I., Witt, M. \& Godley, B. (2012) Status and community-based conservation of marine turtles in the northern Querimbas Islands (Mozambique). Oryx, 46, 359-367.

Greengrass, E. (2011) Exploring the Dynamics of Bushmeat Hunting and Trade in Sapo National Park. Unpublished report. Fauna \& Flora International, Monrovia, Liberia.

Grubb, P., Jones, T.S., Davies, A.G., Edberg, E., Starin, E.D. \& Hill, J.E. (1998) Mammals of Ghana, Sierra Leone and the Gambia. The Tendrine Press, Zennor, UK.
Henschel, P., Coad, L., Burton, C., Chataigner, B., Dunn, A., MacDonald, D. et al. (2014) The lion in West Africa is Critically Endangered. PLoS ONE, 9(1), e8350o.

Hijmans, R.J., Cameron, S.E., Parra, J.L., Jones, P.G. \& Jarvis, A. (2005) Very high resolution interpolated climate surfaces for global land areas. International Journal of Climatology, 25, 1965-1978.

Hillers, A. (2013) Final Report on the Activities of the Research Unit, Across the River-A Transboundary Peace Park for Sierra Leone and Liberia, 2010 to 2013. Unpublished report for BirdLife International/ RSPB.

Hillers, A. \& Muana, A. (2011) Pygmy Hippopotamus Conservation Project Within the "Across the River-A Transboundary Peace Park for Sierra Leone and Liberia” Project (ARTP). Unpublished report for Zoo Basel, Basel, Switzerland.

Hodgkinson, C., Mallon, D., Vogt, T. \& Ransom, C. (2013) First national conservation strategy for the pygmy hippopotamus in Liberia. Oryx, 47, 479-482.

IUCN (2014) The IUCN Red List of Threatened Species v. 2014.2. Http://www.iucnredlist.org [accessed 8 October 2014].

Junker, J., Blake, S., Boesch, C., Campbell, G., Du Toit, L., Duvall, C. et al. (2012) Recent decline in suitable environmental conditions for African great apes. Diversity and Distributions, 11, 1077-1091.

Junker, J., Boesch, C., Freeman, T., Mundry, R., Stephens, C. \& KüHL, H.S. (2015) Integrating wildlife conservation with conflicting economic land-use goals in a West African biodiversity hotspot. Basic and Applied Ecology, 16, 690-702.

Klop, E., Lindsell, J.A. \& SiAKA, A. (2008) Biodiversity of Gola Forest, Sierra Leone. Unpublished report. RSPB and CSSL.

Koroma, P.Y. (2012) Analysis of the distribution of large mammals around the Gola Rainforest National Park (Malema Chiefdom) based on a camera trap study, with a focus on key bushmeat species. BSc thesis. Eastern Polytechnic, Kenema, Sierra Leone.

LAHAI, K. (2013) The distribution of key species in the Gola Forests - a comparison between the Gola Rainforest National Park in Sierra Leone and the Gola National Forest in Liberia. A case study in Gola Central (Nomo, Gaura, Malema and Tunkia Chiefdoms). BSc thesis. Eastern Polytechnic, Kenema, Sierra Leone.

Laurance, W.F., Sayer, J. \& Cassman, K.G. (2014) Agricultural expansion and its impacts on tropical nature. Trends in Ecology \& Evolution, 29, 107-116.

Laurance, W.F., Useche, C., Rendeiro, J., Kalka, M., Bradshaw, C.J.A., SloAn, S.P. et al. (2012) Averting biodiversity collapse in tropical forest protected areas. Nature, 489, 290-294.

LEWISON, R.L. (2011) Family Hippopotamidae (hippopotamuses). In Handbook of the Mammals of the World, Volume 2 (eds D.E. Wilson \& R.A. Mittermeier), pp. 308-319. Lynx Edicions, Barcelona, Spain.

Lewison, R. \& Oliver, W. (IUCN SSC Hippo Specialist Subgroup) (2008) Choeropsis liberiensis. In The IUCN Red List of Threatened Species $v$. 2013.2. Http://www.iucnredlist.org [accessed 8 October 2014].

Mallon, D., Wightman, C., De Ornellas, P. \& Ransom, C. (eds) (2011) Conservation Strategy for the Pygmy Hippopotamus. IUCN Species Survival Commission, Gland, Switzerland \& Cambridge, UK.

Mayaux, P., Bartholomé, E., Fritz, S. \& Belward, A. (2004) A new land-cover map of Africa for the year 2000. Journal of Biogeography, 31, 861-877.

Merz, G. (1986) The status of the forest elephant Loxodonta africana cyclotis, Matschie, 1900, in the Gola Forest reserves, Sierra Leone. Biological Conservation, 36, 83-94.

Mittermeier, R.A., Robles Gil, P., Hoffman, M., Pilgrim, J., Brooks, T., Goettsch Mittermeier, C. et al. (2004) Hotspots 
Revisited: Earth's Biologically Richest and Most Endangered Terrestrial Ecoregions. University of Chicago Press, Chicago, USA.

Monticelli, D., Siaka, A., Buchanan, G.M., Wotton, S., Morris, T., Wardill, J.C. \& Lindsell, J.A. (2012) Long term stability of white-necked picarthartes population in south-east Sierra Leone. Bird Conservation International, 22, 170-183.

Nel, J.L., Roux, D.J., Maree, G., Kleynhans, C.J., Moolman, J., REYERS, B. et al. (2007) Rivers in peril inside and outside protected areas: a systematic approach to conservation assessment of river ecosystems. Diversity and Distributions, 13, 341-352.

Perfecto, I. \& Vandermeer, J. (2010) The agroecological matrix as alternative to the land-sparing/agricultural intensification model. Proceedings of the National Academy of Sciences of the United States of America, 107, 5786-5791.

Phillips, S.J., Anderson, R.P. \& Schapire, R.E. (2006) Maximum entropy modeling of species geographic distributions. Ecological Modelling, 190, 231-259.

Phillips, S.J. \& DUdik, M. (2008) Modelling of species distributions with Maxent: new extensions and a comprehensive evaluation. Ecography, 31, 161-175.

Ransom, C., Robinson, P.T. \& Collen, B. (2015) Choeropsis liberiensis. The IUCN Red List of Threatened Species 2015: e.T10032A18567171. Http://dx.doi.org/10.2305/IUCN.UK.2015-2. RLTS.T10032A18567171.en [accessed 19 March 2016].

Rodrigues, A.S.L., Andelman, S.J., Bakarr, M.I., Boitani, L., Brooks, T.M., Cowling, R.M. et al. (2004) Effectiveness of the global protected area network in representing species diversity. Nature, 428, 640-643.

Roth, H.H., Hoppe-Dominik, B., Mühlenberg, M., Steinhauer-Burkart, B. \& Fischer, F. (2004) Distribution and status of the hippopotamids in the Ivory Coast. African Zoology, 39, 211-224.

S теск, B. (2015) International Studbook for the Pygmy Hippopotamus 2014. Zoo Basel, Basel, Switzerland.

Steinmetz, R., Srirattanaporn, S., Mor-Tip, J. \& Seuaturien, N. (2014) Can community outreach alleviate poaching pressure and recover wildlife in South-East Asian protected areas? Journal of Applied Ecology, 51, 1469-1478.

Swanepoel, L.H., Lindsey, P., Somers, M.J., van Hoven, W. \& DAlerum, F. (2013) Extent and fragmentation of suitable leopard habitat in South Africa. Animal Conservation, 16, 41-50.

Trewhella, W.J., Rodrigues-Clark, K.M., Corp, N., Entwistle, A., Garrett, S.R.T., Granek, E. et al. (2005) Environmental education as a component of multidisciplinary conservation programs: lessons from conservation initiatives for Critically Endangered fruit bats in the western Indian Ocean. Conservation Biology, 19, 75-85.
Tweh, C.G., Lormie, M.M., Koua Kou, C.Y., Hillers, A., Kühl, H.S. \& Junker, J. (2015) Conservation status of chimpanzees Pan troglodytes verus and other large mammals in Liberia: a nationwide survey. Oryx, 49, 710-718.

UN (United Nations) (2015) UN Transforming Our World: The 2030 Agenda for Sustainable Development. Resolution adopted by the General Assembly on 25 September 2015. Https:// sustainabledevelopment.un.org/post2015/transformingourworld [accessed 19 April 2016].

UNDP (United Nations Development Programme) (2014) Human Development Report 2014. Sustaining Human Progress: Reducing Vulnerabilities and Building Resilience. United Nations Development Programme. New York, USA.

UNEP (United Nations Environment Programme) (2015) The World Database on Protected Areas. Http://www.unep-wcmc.org [accessed 1 October 2015].

USGS (U.S. Geological Survey) (2013) HYDRO1 K data. Https:// lta.cr.usgs.gov/HYDRO1K [accessed 17 September 2013].

Vito EARTh ObSERVATION (2010) SPOT vegetation programme. Http://www.spot-vegetation.com/ [accessed 13 September 2013].

Wearn, O.R., Rowcliffe, J.M., Carbone, C., Bernard, H. \& EwErs, R.M. (2013) Assessing the status of wild felids in a highly-disturbed commercial forest reserve in Borneo and the implications for camera trap survey design. PLOS ONE, 8(11), e77598.

Western, D., Russell, S. \& Cuthill, I. (2009) The status of wildlife in protected areas compared to non-protected areas of Kenya. PLoS ONE, 4(7), e6140.

\section{Biographical sketches}

Annika Hillers' work focuses on the sustainable management of protected areas and the conservation of threatened species in West Africa. Graeme Buchanan works primarily on the use of spatial data to answer applied conservation questions, from local to global scales. JERRY GARTEH is a biologist with a strong interest in practical conservation and human-wildlife interactions in Liberia. SOLOMON Томму has a special interest in community involvement for the effective protection of natural habitats and threatened species in Sierra Leone. MoHAMED Fof AN A works to facilitate the monitoring of wildlife populations to contribute to the effective management of protected areas and their biodiversity in Sierra Leone. JEREMY LiNDSELL works on a range of practical tropical forest conservation projects and is interested in the role of protection and the impact of degradation on tropical forests and their threatened species. 